\title{
The Y graft: Myocardial revascularization with both internal thoracic arteries
}

\section{Evaluation of eighty cases with coronary angiographic assessment}

The use of bilateral in situ internal thoracic arteries is restricted by the risk of sternal devascularization, the length of the pedicle, and the necessity to avoid crossing the midline. The aim of this study is to evaluate $\mathrm{Y}$ grafts achieved by anastomosing the proximal end of the free right internal thoracic artery to the side of the attached left internal thoracic artery. Y grafts were performed in 80 patients, aged 41 to 74 years (mean age 58.6 years) between May 1991 and September 1992. Two different techniques were used. Thirty-four patients were included in group 1 and 46 in group 2. Seventy-nine grafts were performed from the left internal thoracic artery to the left anterior descending artery. The right internal thoracic artery was anastomosed to the diagonal artery (5 times), the marginal branch (67 times), the circumflex artery ( 7 times) and the right coronary artery ( 2 times). Seventy-five complementary saphenous vein bypasses were performed in 58 patients. Operative mortality was $2.5 \%$. Two patients had perioperative myocardial infarcts $(2.5 \%)$ on nonbypassed sites. Three patients had sternal wound infections $(3.7 \%)$. Sixty-two patients $(80 \%)$ were reexamined by angiography at month 6-25 in group 1 and 37 in group 2. Sixty left internal thoracic artery bypass grafts $(97 \%)$ were patent versus 39 right internal thoracic artery bypass grafts $(63 \%)$. In group 1, 23 of 25 left internal thoracic artery bypass grafts were patent $(92 \%)$ versus 12 right internal thoracic artery grafts $(\mathbf{4 8} \%)$. In group 2, all 37 left internal thoracic artery bypass grafts were patent $(100 \%)$ versus 27 right internal thoracic artery grafts $(73 \%)$. With this procedure, particular attention must be paid to the length of the right internal thoracic artery, and extensive training is required. ( $J$ THORAC CARDIOVASC SURG 1994;108:736-40)

Sidney Chocron, MD, ${ }^{a}$ Joseph-Philippe Etievent, MD, ${ }^{a}$ François Schiele, MD, ${ }^{b}$ François Clement, MD, ${ }^{a}$ Kifah Alwan, MD, ${ }^{a}$ Anne Cordier, MD, ${ }^{a}$ Nicole Schipman, MD, and Jean-Louis Mourand, MD, ${ }^{\text {a Besancon, France }}$

$T_{\text {h }}$ he left internal thoracic artery (LITA) is the best graft for bypassing stenoses of the left anterior descending coronary artery (LAD). ${ }^{1-3}$ The current trend in myocardial revascularization is to use arterial grafts often, if not systematically.

From the Departments of Thoracic and Cardiovascular Surgery ${ }^{a}$ and Cardiology, b Hôpital Saint-Jacques, Besancon, France.

Received for publication Nov. 8, 1993.

Accepted for publication Mar. 9, 1994.

Address for reprints: Sidney Chocron, MD, Department of Thoracic and Cardiovascular Surgery, Hôpital Saint-Jacques, 25030 Besancon Cedex, France.

Copyright 1994 by Mosby-Year Book, Inc.

$0022-5223 / 94 \$ 3.00+0 \quad 12 / 1 / 55991$
The right internal thoracic artery (RITA), used in the same circumstances as the LITA, may offer the same results. ${ }^{4-6}$ Therefore, the use of bilateral in situ internal thoracic artery (ITA) grafts has gained prominence. This development is however restricted by three factors: the risk of sternal devascularization and ischemia resulting in sternal wound complications, ${ }^{7,8}$ insufficient length of the RITA pedicle, and the necessity to cross the midline. ${ }^{9}$

Barra and associates ${ }^{10,11}$ proposed the $\mathrm{Y}$ procedure carried out by anastomosing the proximal end of the free RITA to the side of the attached LITA. This procedure provides additional length to reach a distal coronary artery branch and reduces sternal devascularization by preserving the first RITA collateral artery. RITAs and LITAs are identical as to their size, wall thickness, and 
low susceptibility to atherosclerosis. The purpose of this study is to evaluate graft patency with this surgical procedure.

\section{Patients and methods}

This procedure was performed in patients requiring myocardial revascularization when coronary arteries were not close enough to allow bilateral in situ grafting. Exclusion criteria were age older than 65 years, diabetes mellitus, and severe respiratory insufficiency except when saphenous vein grafts (SVGs) were unusuable.

Surgical technique. The ITAs are dissected from the chest wall along with a large pedicle of surrounding tissues with the aid of electrocautery and hemoclips. The RITA is dissected from the origin of the second collateral artery to the last bifurcation. The LITA is dissected from the first collateral artery to the distal bifurcation. The connections of the ITAs are left intact. After heparinization, the RITA is removed as a free graft and the last bifurcation of the LITA is divided. The $\mathrm{Y}$ anastomosis between the ITAs can be performed with or without cardiopulmonary bypass.

Both arteries are placed onto a thick pad laid on the aorta and therefore are fairly superficial, which facilitates the anastomosis. A $1 \mathrm{~cm}$ incision is made in the LITA and the proximal end of the RITA is anastomosed with a continuous 8-0 monofilament suture. Two 5-0 monofilament stitches link the two pedicles where the ITAs deviate from each other. In this way, a Y graft is made from two distal ITA segments.

The LITA forms the short leg of the Y graft, and the RITA, the long leg. The length of the RITA makes it possible to graft as far as the lateral circumflex or posterior descending arteries. The ascending aorta is cannulated and a two-staged venous cannula is introduced into the right atrium. Cardiopulmonary bypass and ischemic arrest are used. The myocardium is protected with antegrade crystalloid cardioplegia (average 800 $\mathrm{ml})$ and epicardial icing. Cardioplegic solution $(100 \mathrm{ml})$ is injected into the aortic root after each anastomosis.

Operative techniques were not the same in all patients. In the 34 first patients (group 1) anastomosis between the ITAs was performed after coronary artery anastomosis, and the RITA was anastomosed on the nonpleural side of the LITA. In the following 46 patients (group 2), anastomosis between the ITAs was achieved after heparinization but before coronary artery anastomosis, and the RITA was anastomosed on the pleural side of the LITA. Achieving the optimum graft length was easier with the second method.

Patient follow-up. All patients were examined at month 3 of the postoperative course. After undergoing cardiac technetium scintigraphy and pulmonary radiography, patients were questioned and, while maintaining their usual medication, were given a stress test to detect recurrent coronary angina. Angiography was carried out at month 6 with the patient's consent. This was performed by selective catheterization of the LITA, with injection of a contrast medium.

\section{Results}

Between May 1991 and September 1992, we performed 345 myocardial revascularizations. The $Y$ procedure was carried out in 80 patients. Group 1 patients $(n=34)$ were operated on between May and December
Table I. Preoperative status

\begin{tabular}{lcc}
\hline & Group 1 & Group 2 \\
\hline Mean age (yr) & $61 \pm 8$ & $57 \pm 8$ \\
NYHA angina class & 1 & 1 \\
I & 14 & 28 \\
II & 9 & 10 \\
III & 10 & 7 \\
IV & & \\
Myocardial infarction & 7 & 4 \\
Anteroseptal & 2 & 3 \\
Lateral & 10 & 12 \\
Inferior & & \\
Risk factors & 20 & 28 \\
Smoking & 25 & 28 \\
Dyslipidemia & 4 & 6 \\
Diabetes mellitus & 12 & 15 \\
Hypertension & 7 & 11 \\
Obesity & 10 & 12 \\
Previous family history & 6 & 6 \\
Arteritis & & \\
Angiographic characteristics & 7 & 12 \\
Bitroncular & 17 & 19 \\
Tritroncular & 3 & 4 \\
LMCA disease & 7 & 11 \\
LMCA + RCA disease &
\end{tabular}

$N Y H A$, New York Heart Association; $L M C A$, left main coronary artery; $R C A$, right coronary artery.

1991, and group 2 patients $(n=46)$ between January and September 1992.

Preoperative data (Table I). The two groups did not differ significantly with regard to the distribution of mean age, risk factors, preoperative symptoms, and number of diseased vessels.

Operative data (Table II). An average of three bypass grafts per patient (two to five) were performed. The LITA was used to bypass the LAD in 79 cases and the marginal coronary artery in one case. In three instances the LITA was used as a sequential graft over the diagonal artery and the LAD.

The RITA was used to bypass a marginal artery in 66 cases, the circumflex artery in six, the diagonal artery in five, the right coronary artery in two instances, and the LAD in one. A sequential graft over the marginal and circumflex arteries was performed. Seventy-five complementary SVG bypass grafts were performed in 58 patients.

Postoperative results. Two patients died during the perioperative course $(2.5 \%)$. One patient requiring an intraaortic balloon pump died in the intensive care unit. Another patient whose initial postoperative course was event-free died of mesenteric infarction on day 3. This patient had diffuse arteritis, and a carotid endarterectomy was performed during the bypass operation. 
Table II. Location of ITA grafts

\begin{tabular}{lccccc}
\hline & \multicolumn{2}{c}{$\begin{array}{c}\text { Group I } \\
\text { (34 patients) }\end{array}$} & & \multicolumn{2}{c}{$\begin{array}{c}\text { Group 2 } \\
\text { (46 patients) }\end{array}$} \\
\cline { 2 - 3 } \cline { 5 - 6 } & $\begin{array}{c}\text { Left } \\
\text { branch }\end{array}$ & $\begin{array}{c}\text { Right } \\
\text { branch }\end{array}$ & & $\begin{array}{c}\text { Left } \\
\text { branch }\end{array}$ & $\begin{array}{c}\text { Right } \\
\text { branch }\end{array}$ \\
\hline Left anterior descending & 34 & 0 & & 45 & 0 \\
Diagonal artery & $1^{*}$ & 2 & & $2^{*}$ & 3 \\
Marginal artery & 0 & 27 & & 1 & 40 \\
Circumflex artery & 0 & 3 & & 0 & $4^{*}$ \\
Right coronary artery & 0 & 2 & & 0 & 0 \\
\hline
\end{tabular}

*Sequential grafts.

Two patients had perioperative myocardial infarcts. Pericardial extravasation occurred and necessitated drainage in three patients. In three patients sternal wound infections (3.7\%) necessitated closed-chest irrigation and drainage.

Functional results. Among the 78 patients examined 3 months after the operation, 73 were free of symptoms and five had class II recurrent angina. No deaths or myocardial infarctions occurred after discharge.

Results of angiographic reexamination (Fig. 1). Angiographic reexamination was proposed to 78 patients. Eleven symptom-free patients refused, and angiography could not be performed in five patients. Sixty-two patients $(80 \%)$ were reexamined by angiography at month $6-25$ in group 1 and 37 in group 2. Sixty LITA bypass grafts $(97 \%)$ were patent versus 39 RITA grafts $(63 \%)$. In group 1, 23 of 25 LITA bypass grafts (92\%) were patent versus 12 RITA grafts (48\%). In group 2, all 37 LITA bypass grafts $(100 \%)$ were patent versus 27 RITA grafts $(73 \%)$.

Table III shows the location of occluded grafts. Stenosis of the LITA-coronary anastomosis was found in two symptom-free patients. Transluminal coronary angioplasty was efficient in both. Stenosis in the RITA-LITA anastomosis was not detected in any patient.

\section{Discussion}

The lower patency of SVGs compared with ITA grafts $^{3}$ explains the trend to optimize ITA grafts with complex procedures and not merely perform the usual LITA bypass to the LAD. ${ }^{4,12,13}$ The Y procedure makes it possible to reach distal branches of coronary vessels and to bypass the LAD with the attached LITA and therefore avoid the main drawbacks of bilateral in situ ITA grafting. Our mortality rate compares favorably with data reported by other authors. $4,13,14$

The $Y$ procedure and sternal wound infection. In this series, the sternal wound infection rate $(3.7 \%)$ was higher than our usual average rate (1.6\%). Carrier and asso-
Table III. Location of occluded grafts

\begin{tabular}{|c|c|c|c|c|}
\hline & \multicolumn{2}{|c|}{$\begin{array}{c}\text { Group } 1 \\
(25 \text { patients })\end{array}$} & \multicolumn{2}{|c|}{$\begin{array}{c}\text { Group } 2 \\
\text { (37 patients) }\end{array}$} \\
\hline & $\begin{array}{c}\text { Left } \\
\text { branch } \\
(O / R)\end{array}$ & $\begin{array}{c}\text { Right } \\
\text { branch } \\
(O / R)\end{array}$ & $\begin{array}{c}\text { Left } \\
\text { branch } \\
(O / R)\end{array}$ & $\begin{array}{c}\text { Right } \\
\text { branch } \\
(O / R)\end{array}$ \\
\hline Left anterior descending & $2 / 25$ & 0 & $0 / 37$ & 0 \\
\hline Diagonal artery & $0 / 1$ & $1 / 2$ & $0 / 2$ & $1 / 3$ \\
\hline Marginal artery & 0 & $10 / 18$ & 0 & $8 / 32$ \\
\hline Circumflex artery & 0 & $2 / 3$ & 0 & $1 / 2$ \\
\hline Right coronary artery & 0 & $0 / 2$ & 0 & 0 \\
\hline
\end{tabular}

$O / R$, Number of occluded grafts/number of restudied grafts.

ciates ${ }^{7}$ showed that double ITA harvesting led to significantly more severe sternal hypoperfusion than single ITA harvesting. Hypoperfusion may be responsible for the development of sternal wound infection but it is probably not the only factor. The risk of sternal hypoperfusion is similar in diabetic and nondiabetic patients, ${ }^{7}$ whereas infectious risk is higher in diabetic patients. ${ }^{8}$ Hazelrigg and colleagues ${ }^{8}$ showed clinically that the risk of wound complication was nearly five times greater with bilateral ITA grafting than with SVG and three times greater than the risk with single ITA grafting. In our series, 117 patients underwent revascularization by bilateral in situ ITA grafts with a sternal wound infection rate of $0.9 \%$. Although the difference between the two series was not significant, preservation of the first collateral artery of the RITA did not prevent sternal wound infection.

The overall results of coronary angiography showed a satisfactory patency rate of the LITA (97\%). One might surmise that an additional anastomosis between the ITAs would reduce LITA patency rate, but this was not so inasmuch as the anastomosis was easily performed. The ITAs are identical in diameter and thickness and are rarely atheromatous. The main risk is injury to the intima of opposite wall during arteriotomy of the LITA.

The poor results obtained in group 1 are due more to a necessary experience curve than to the technical difference between the two groups. Anastomosing the RITA on the nonpleural side of the LITA in group 1 was not a good solution. The weight of the RITA tended to twist the LITA on its axis, consequently necessitating numerous fixations on the epicardium.

The main difficulty is to have an RITA of optimum length. Too much length may cause plication, which hinders perfect positioning and provokes thrombosis.

The $Y$ procedure versus free aorta-coronary graft. Patency of the LITA in our series is similar to previously published data on in situ LITA grafts, 2, 3,15, 16 and our 


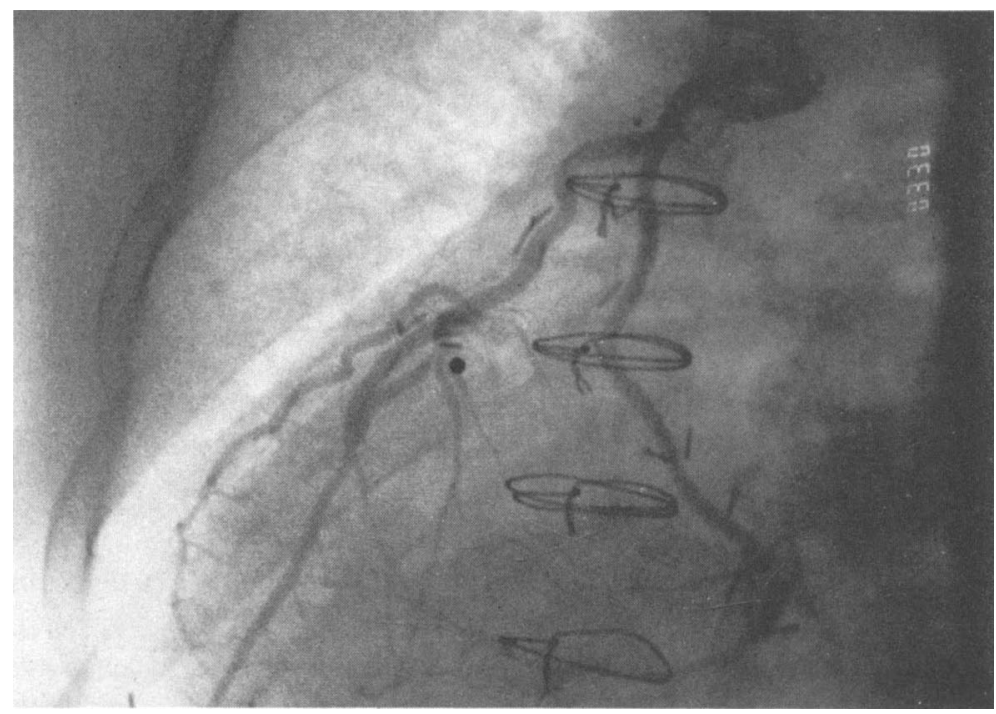

Fig. 1. Angiographic assessment of the Y procedure. The attached LITA bypasses the LAD, and the RITA bypasses the circumflex artery.

RITA patency rate compares with the results described by Loop and associates ${ }^{9}$ on free aorta-coronary ITA grafts. These'results show the attached graft to be more adaptable than the free graft. Yang, Oemar, and Luscher ${ }^{17}$ believe that the better patency of ITAs than of SVGs is due to antithrombotic features, low proliferative response, and better vasomotoricity of ITAs. Loss of both proximal and distal connections of the free graft might alter vasomotoricity, whereas antithrombotic and proliferative features appear to be preserved in vitro. ${ }^{17}$

The $Y$ procedure versus bilateral in situ ITA grafts. When both ITAs are pedicled, RITA patency rate is inferior to that of the LITA ( $85 \%$ versus $92 \%)^{13}$ This inferior patency is probably due to the length of the graft. It is often necessary to use the end part of the ITA for grafting; hence the diameter is smaller. $\mathrm{He}^{18}$ showed that "the reactivity of the distal section of the internal mammary artery is inversly correlated to the diameter.... This suggests that trimming off the distal end of the internal mammary artery as much as possible may be the best way to prevent graft spasm and that superior results of the left internal mammary artery grafted to the left anterior descending artery or the use of a 'free graft' may be related to the shorter length ... and less contractility of the graft." The Y procedure allows a shorter graft length on both legs.

\section{Conclusion}

The clinical results obtained with the $Y$ procedure are satisfactory. Angiographic reexamination showed good patency of the LITA (97\%). RITA patency was less satisfactory $(73 \%)$. The advantage of the Y procedure over use of the free aorta-coronary graft is the easier, more reliable achievement of anastomoses between the ITAs when the aorta is atheromatous or even calcified, as is often the case. Compared with the use of bilateral in situ ITA grafts, the $Y$ technique solves the graft length problem, makes it possible to trim off the distal end of the ITA, and thus prevents graft spasm. The Y procedure reduces sternal devascularization by preserving the first collateral artery of the RITA, although in our series preserving the circulation did not lead to a decrease in the sternal wound infection rate. The $\mathrm{Y}$ procedure also saves crossing the midline with the RITA, which is beneficial in case of reoperation.

With the Y procedure, particular care must be taken with the ITAs, and the correct graft length must be estimated accurately. This procedure requires extensive training.

\section{REFEREN CES}

1. Loop FD, Lytle BW, Cosgrove DM, et al. Influence of the internal mammary artery graft on 10-year survival and other cardiac events. N Engl J Med 1986;314:1-6.

2. Godenir JP, Danchin N, Amrein D, et al. Ten year results of anastomoses of the left internal mammary artery to the anterior interventricular artery. (In French.) Ann Chir 1987;41:393-6.

3. Lytle BW, Loop FD, Cosgrove DM, Ratliff NB, Easley K, Taylor PC. Long-term (5 to 12 years) serial studies of 
internal mammary artery and saphenous vein coronary bypass grafts. J THORAC CARdIOvaSC SuRG 1985;89:24858.

4. Fiore AC, Naunheim KS, McBride LR, et al. Fifteen-year follow-up for double internal thoracic artery grafts. Eur $\mathrm{J}$ Cardiothorac Surg 1991;5:248-52.

5. Morris JJ, Smith LR, Jones RH, et al. Influence of diabetes and mammary artery grafting on survival after coronary bypass. Circulation 1991;84(Suppl):III275-84.

6. Dion R, Etienne P, Verhelst R, et al. Bilateral mammary grafting: clinical, functional and angiographic assessment in 400 consecutive patients. Eur J Cardiothorac Surg 1993; 7:287-94.

7. Carrier M, Gregoire J, Tronc F, Cartier R, LeClerc Y, Pelletier LC. Effect of internal mammary artery dissection on sternal vascularization (see comments). Ann Thorac Surg 1992;53:115-9.

8. Hazelrigg SR, Wellons HA Jr, Schneider JA, Kolm P. Wound complications after median sternotomy: relationship to internal mammary grafting. J THORAC CARDIOVASC SURG 1989;98:1096-9.

9. Loop FD, Lytle BW, Cosgrove DM, Golding L, Taylor PC, Stewart RW: Free (aorta-coronary) internal mammary artery graft. J THORAC CARDIOVASC SURG 1986;92:82731.

10. Barra JA, Mondine P, Mahlab A, et al. Right internal mammary artery reimplantation into the left internal mammary artery: $\mathrm{Y}$ anastomosis. 25 cases. (In French.) Ann Chir 1991;45:661-6.
11. Barra JA, Mondine P, Bezon E, Mahlab A, Rukbi I, Brarsco J. Revascularization of coronary arteries: reimplantation of the right internal mammary artery into the left in situ mammary artery. (In French.) Presse Med 1991; 20:423-5.

12. Galbut DL, Traad EA, Dorman MJ, et al. Twelve-year experience with bilateral internal mammary artery graft. Ann Thorac Surg 1985;40:264-70.

13. Galbut DL, Traad EA, Dorman MJ, et al. Seventeen-year experience with bilateral internal mammary artery grafts. Ann Thorac Surg 1990;49:195-201.

14. Robin J, Zabot JM, Eker A, Diab C, Revel D, Chassignolle JF. Use of the internal mammary artery as a free graft with reimplantation of the proximal end onto the ascending aorta. A propos of 39 cases. (In French.) Ann Chir 1992; 46:700-4.

15. Ivert T, Huttunen K, Landou C, Björk VO. Angiographic studies of internal mammary artery grafts 11 years after coronary artery bypass grafting. J THORAC CARDIOVASC SURG 1988;96:1-12.

16. Barner HB, Standeven JW, Reese J. Twelve-year experience with internal mammary artery for coronary artery bypass. J ThORAC CARdiovasc SuRg 1985;90:668-75.

17. Yang Z, Oemar B, Luscher TF. Mechanism of coronary bypass graft disease. (In German.) J Suisse Med 1993; 123:422-7.

18. He GW. Contractility of the human internal mammary artery at the distal section increases toward the end. J THORAC CARdiovasC SURG 1993;106:406-11. 